\title{
Teaching Exploration of Instrumental Analysis Experiment in University
}

\author{
Zhang zhen $1 \mathrm{e}^{1.2} / \mathrm{s}$ per 1 st Affiliation \\ (*Corresponding Author) \\ 1 Key Laboratory of Advanced Civil Engineering \\ Materials (Tongji University), Ministry of Education \\ 2 School of Materials Science and Engineering. Tongji \\ University \\ Shanghai, China \\ annyz5664@sina.com
}

\author{
Wu Jianguo/s per 2nd Affiliation \\ School of Materials Science and Engineering. \\ Tongji University \\ Shanghai, China \\ wjg@tongji.edu.cn
}

\begin{abstract}
Instrumental analysis is a basic course for chemistry, pharmacy and food, and plays a very important role in cultivating talents for industry and the society. In the instrument analysis experiment course, the students can not only understand the structure and working principle of instruments, but also get familiar with the operation method of instrument. Facing the current status of less time of instrumental operation, less enthusiasm of learning and poor effect of teaching for instrumental analysis experiment, according to the characteristics of instrument analysis experiment, the author puts forward the corresponding reform measures from the aspects of new teaching content, new teaching mode, and the application of multimedia courseware, in order to improve the teaching quality of instrumental analysis experiment. The results show that the reform can enhance teaching effect and it is of great help to students learning autonomy, which helped to guide the majors to have more initiative and freedom in learning rather than receiving knowledge passively.
\end{abstract}

Keywords-Instrumental Analysis Experiment; Teaching Reform; Teaching Mode; Open Experiment Platform; Multimedia Courseware

\section{INTRODUCTION}

China's famous physicist Feng Duan once said: "laboratory is the heart of the modern university. The importance of laboratory cannot be overvalued." Laboratories, as the basis for practical teaching and scientific research in universities, have played an extremely important role in national knowledge innovation systems and personnel training. In the current higher education, instrumental analysis experiment has been an important part of learning system in colleges and universities, receiving more and more people's attention. Experiment course has offered a platform for the combination of theory and practice, it is an important means of the training skills, cultivate the innovative consciousness and ability [1-5]. However, traditional Chinese education has placed the most emphasis on basic knowledge, ignoring the cultivation of innovation and exploration. The students have far too much faith in the books, with a lack of aggressiveness. This condition limits students' practical ability, skills, interests, and innovative ability. How to create an advanced experiment environment and use techniques to stimulate student's motivation in learning and creative spirits is really a new topic facing us [6]. It is very necessary and urgent to conduct the reform. In this paper, the author updated the traditional methods for experiment, supplies students with an open experiment platform, and developing multimedia tutorial. As a result, progress of instrument analysis experiment teaching has been promoted and gained obvious teaching achievements.

\section{CURRENT SITUATION OF INSTRUMENT ANALYSIS EXPERIMENT COURSE}

\section{A. The Course Lacks Systematicness and Continuity}

Due to the limitation of teaching hours, the experiment teachers always tend to put the sample pretreatment, and the selection process of test condition is omitted. Then, the students do the test with the sample and the ordered process knowing nothing about the preparations. All these results in that students are not able to acquire necessary experiment methods, make the best use of or update the limited knowledge they obtain, not to mention flexible application and creativity. Meanwhile, some experiment has been lasting for decades; seriously behind the development of modern instrument science, and experiment content also has a serious discrepancy with the reality of scientific and technological achievements and the production needs [1].

\section{B. Traditional Teaching Lacks Independence}

Traditionally, students taking experiment according to the experimental guidance with the steps are all written in a very detailed. The students do not need themselves to think, analyze and solve problems. As a result, the students are restricted to an elementary level and they are at sea about the combination of experimental content and experimental operation after they have finished the course. Such assessment to some degree goes against stimulating initiatives, independence and creative ability [7].

\section{The Course Less of Hands-on Opportunities}

The traditional experiment teaching is always teachercentered class, but the students in general mark subordinate status. The teacher introduced the main 
experimental methods, experimental procedures, data measurement, and the issues needs to pay attention to in experiments. Although the majority of students have wanted to make experiments, but they still have few chances to have a try to hand-on the instrument.

\section{REFORM OF INSTRUMENT ANALYSIS EXPERIMENT TEACHING}

\section{A. The Reform of Teaching Mode and Teaching Content}

The traditional experiment teaching is always teachercentered class and the pattern has been proved to be outmoded and method rigid. In order to change this phenomenon, the instrument analysis experiment class need to rebuild under the background as the class is the center, the core activity-as the carrier, a student-based, teacher-driven curriculum system of three-dimensional. That is a process in which the students discover problems, inquiry them and make experiment initiatively with the help of their teachers, so that it becomes an integral part of the educational work of subordination class which is the extension and important supplement of the main class. Next, in order to change the experiment course is not in system, students are required to participate in all aspects of test preparative work, from the preparation of the reagents to the instrumentation calibration. In this way, by preparing a test can students make accumulate experience, training the basic experimental skills. Again, the experiments with difficulty give the students the confidence to complete and the corresponding exercise [8, 9]. Finally, the experiment content should be reasonably arranged to keep up with development of instrument, which can promote the students' interest in learning [10].

\section{B. Supply Students with an Open Platform}

Traditional experiments allow students operating the instrument in laboratory only on class and instruments seldom open to students. Students are not able to achieve operate instruments skillfully. Therefore, supplying students with an open platform is very necessary. Open experiment platform can provide students with abundant test time. The students use their spare time to get familiar with the structure of the instrument, and practice the use of instrument. The open laboratory can also offer some simple explorative experimental project to the students. In the process, each student has undergone a complete scientific research and practical experience, taste the taste of the innovation of scientific research. Therefore, integrity experiment was one of the means to cultivate students' ability of innovation and practicing. The results showed that opening experiment cannot be replaced by basic experiment in developing ability of manual operation and cultural and scientific qualities.

\section{Multimedia Teaching}

Along with the vigorous development of science, technology and the computer technology, the multimedia teaching technology is more and more demonstrating its superiority. Multimedia courseware applies many kinds of media information, such as text, image, video frequency, voice, to construct the circumstances of computer assisted instruction directly and actively. The application of multimedia technology makes the contents of course become sensible and imaginary, arouses the student's study interest, and increases the course's teaching efficiency. Although using the multimedia teaching in the teaching process to have many merits of traditional educations, it is worth noting that during multimedia teaching people should achieve organic combination of teaching method and leave enough time and space for students to think and communicate.

\section{CONCLUSIONS}

In the traditional experiment teaching work, there are some problems that teaching is not integrated, limiting the development of the students' comprehensive ability and unsuitable to cultivate the innovative abilities. This paper indicated the problems and some suggestions of teaching reform were presented. First, the educational mode, the teaching contents and the teaching skill should be implanted in experimental classes to get a new way in cultivating creativity by experimental teaching. Second, Opening laboratory can improve model of instruction and increase study ability and interest of students on the experimental lessons. Third, the multimedia educational model impelled the experiment course development. However, with the rapid development of instrument, people should strive to explore new experiment teaching modes to keep pace with the times.

\section{ACKNOWLEDGMENT}

The project was supported by Key Laboratory of Advanced Civil Engineering Materials (Tongji University) of China, Ministry of Education (201308); teaching reform project of Tongji University (0500104068); the instrumental measurement fund of Tongji University (0002014102).

\section{REFERENCES}

[1] Xu Jiang-chun, Wu Jian-de, Lin Nan, et al. Based on selfmanufactured experimental equipments, the curriculums of microcomputer experiment teaching mode reform and innovation [C] // Advances in Multimedia, Software Engineering and Computing, Springer Berlin Heidelberg, 2012:375-381

[2] Flemming Sørensen, , Jan Mattsson, , Jon Sundbo. Experimental methods in innovation research [J]. Research Policy, 2010, 39(3):313-322.

[3] Zhang Jin-hua, Laboratory construction and management of newly-upgraded graduate colleges $[\mathrm{J}]$. Journal of Taiyuan University, 2013, 14(4):117-118.

[4] Liu Bo. Theoretical research of laboratory construction and management in universities [J]. Laboratory Science, 2015, 18(1):190-192.

[5] Zhao Li-hua, Dai Chao-qing, Wang Yue-yue. Reform on college physics experiment teaching for engineering students in agriculture and forestry universities [C] // 2012 7th International Conference on Computer Science\&Education (ICCSE), Melbourne: IEEE, 2012:2007-2011.

[6] Sun Sheng-qi, Dong Liang. Reform and research on the automation experiment teaching with the network condition [C]// 2012 2nd International Conference on Consumer Electronics, Communications and Networks (CECNet), IEEE, 2012:2765-2768.

[7] Zhou Xue-bing, Xu Lei, Chen Rong-xu. Research on construction and management of laboratory technician teams in Universities [J]. Laboratory Research and Exploration, 2015, 34(2):243-245.

[8] Yu Zhuan-ni, Wang Qiang. Exploration and study in instrumental analysis experiment teaching [J]. Laboratory science, 2013 16(1):69-73 
[9] Cui Lian-yi. Practice of reform in instrumental analysis experiment teaching [J]. Research and exploration in laboratory, 2011, 30(2):189-192

[10] Wang Li, Wang Fu-zhong, Su Bo. Reform on experiment teaching of single-chip microcomputer and cultivation of students' practical ability. [C]// E-Health Networking, Digital Ecosystems and Technologies (EDT), 2010 International Conference on, IEEE, 2010:263-266 